\title{
Rare Earth Coordination Catalysts for the Polymerization of Alkylene Oxides I. Polymerization of Epichlorohydrin ${ }^{\dagger}$
}

\author{
Jian Wu and Zhiquan SHEN \\ Chemistry Department, Zhejiang University, Hangzhou, P.R. China
}

(Received October 23, 1989)

\begin{abstract}
Acetylacetonates of nine rare earth elements, combined with triisobutylaluminum and water, were used as catalysts for the polymerization of epichlorohydrin $(\mathrm{ECH})$. It was found that the $\mathrm{Nd}(\mathrm{acac})_{3}-\mathrm{Al}(\text { iso- } \mathrm{Bu})_{3}-\mathrm{H}_{2} \mathrm{O}$ system was a favourable catalyst for polymerization with respect to preparing polyepichlorohydrin $(\mathrm{PECH})$ with high molecular weight and low crystallinity. The polymerization of $\mathrm{ECH}$ with $\mathrm{Nd}(\mathrm{acac})_{3}-\mathrm{Al}(\text { iso- } \mathrm{Bu})_{3}-\mathrm{H}_{2} \mathrm{O}$ catalyst system was investigated concerning the dependence of polymerization catalyst composition, i.e., $\mathrm{Al} / \mathrm{Nd}$ and $\mathrm{H}_{2} \mathrm{O} / \mathrm{Al}$ molar ratios, polymerization time, and solvent, etc. THF polymerization catalyzed by $\mathrm{Nd}(\mathrm{acac})_{3}-\mathrm{Al}$ (iso$\mathrm{Bu})_{3}-\mathrm{H}_{2} \mathrm{O}$ was also performed to check the character of the catalyst system. The bimetallic nature of the catalyst was proposed.

KEY WORDS Catalyst / Rare Earth Coordination Catalyst / Ring-Opening Polymerization / Epichlorohydrin / Polymerization of Epichlorhydrin
\end{abstract}

Because of the growing significance of epichlorohydrin $(\mathrm{ECH})$ elastomers in practice, various catalysts for the polymerization of alkylene oxides have been developed in the recent decades, e.g., the systems of $\mathrm{AlR}_{3}-\mathrm{H}_{2} \mathrm{O}$ third component, ${ }^{1,2} \mathrm{AlR}_{3}$-strong phosphoric acid-Lewis base, ${ }^{3}$ and $\mathrm{AlR}_{3}-$ nitrogen containing organozinc. ${ }^{4}$ There are two important and necessary characteristics for ECH polymers to obtain useful elastomers: high molecular weight and low crystallinity. We first reported $^{5-9}$ that rare earth compounds combined with alkylaluminum and water were highly effective catalysts for propylene oxide and/or ethylene oxide polymerization. A recent study showed that the ternary systems consisting of rare earth acetylacetonate RE$(\mathrm{acac})_{3}$, alkylaluminum, and water were favourable catalysts to prepare poly(epichlorohydrin) $(\mathrm{PECH})$, with respect to the above points. This paper reports our extensive study on $\mathrm{Nd}(\mathrm{acac})_{3}-\mathrm{Al}(\text { iso- } \mathrm{Bu})_{3}-\mathrm{H}_{2} \mathrm{O}$ catalyst sys- tem for ECH polymerization.

\section{EXPERIMENTAL}

\section{Materials}

$\mathrm{ECH}$ and other monomers used in this paper, like propylene oxide (PO), allyl glycidyl ether (AGE), and tetrahydrofuran (THF), were refluxed over $\mathrm{CaH}_{2}$ and distilled before use. Toluene of analytical reagent was dried with molecular sieve 4A overnight. Triisobutylaluminum $\mathrm{Al}(\text { iso- } \mathrm{Bu})_{3}$ was used as purchased from Roth. Co. Rare earth acetylacetonates RE$(\mathrm{acac})_{3}$, were prepared and purified according to the reference. ${ }^{10}$

\section{Catalyst Preparation and Polymerization}

All procedures were carried out in an atmosphere of purified nitrogen. Water at a certain $\mathrm{H}_{2} \mathrm{O} / \mathrm{Al}$ molar ratio was added dropwise to a solution of $\mathrm{Al}(\mathrm{iso}-\mathrm{Bu})_{3}$ in toluene at $10^{\circ} \mathrm{C}$. After alkane gas evolution had ceased,

\footnotetext{
${ }^{\dagger}$ This work was financed by National Natural Science Foundation of China.
} 
the solution was heated at $60^{\circ} \mathrm{C}$ for $2 \mathrm{~h}$. The reaction mixture thus obtained was a colourless and transparent solution.

$\mathrm{Al}(\text { iso- } \mathrm{Bu})_{3}-\mathrm{H}_{2} \mathrm{O}$ solution was transferred with a tight syringe into a bottle in which a prescribed amount of $\operatorname{RE}(\mathrm{acac})_{3}$ had been put. A homogeneous solution was soon formed. The resultant catalyst solution was aged for $1 \mathrm{~h}$, and then toluene and $\mathrm{ECH}$ were added. The polymerization was terminated by adding excess methanol containing a small amount of $\mathrm{HCl}$. The polymer precipitated was washed with methanol and dried in vacuum.

\section{Measurements}

Inherent viscosity of $\mathrm{PECH}$ was determined in cyclohexanone at $50^{\circ} \mathrm{C}$ by Ubbelohde-type viscometer. The viscosity-average-molecular weight $\bar{M}_{v}$ was calculated by following equation $^{11}$ :

$$
[\eta]=2.51 \times 10^{-5} \bar{M}_{v}^{0.87}
$$

The crystallinity of PECH $\left(x_{\mathrm{c}} \%\right)$ was calculated as follows ${ }^{12}$ :

$$
x_{\mathrm{c}} \%=100 \times \Delta H_{\mathrm{f}} / \Delta \bar{H}_{\mathrm{f}}
$$

where $\Delta \bar{H}_{\mathrm{f}}=27.27 \mathrm{calg}^{-1}$, is the theoretical heat of fusion of PECH crystal, and $\Delta H_{\mathrm{f}}$ is the heat of fusion of a given $\mathrm{PECH}$ sample which was measured with a CDR-1 Calorimeter. ${ }^{1} \mathrm{H}$ NMR spectrum of PECH was obtained on a JEOL FX-90Q NMR spectrometer, using $\mathrm{CDCl}_{3}$ and TMS as the solvent and internal reference, respectively.

\section{RESULTS AND DISCUSSION}

Combinations of nine rare earth acetylacetonates $\mathrm{RE}(\mathrm{acac})_{3}$, with $\mathrm{Al}$ (iso- $\left.\mathrm{Bu}\right)_{3}$ and $\mathrm{H}_{2} \mathrm{O}$, were used as polymerization catalysts for $\mathrm{ECH}$, as shown in Table I. The results of polymerization with $\mathrm{Al}$ (iso- $\mathrm{Bu})_{3}-\mathrm{H}_{2} \mathrm{O}(1: 0.5)$ catalyst system are also listed in Table I for comparison. It was found that with the addition of $\mathrm{RE}(\mathrm{acac})_{3}$ to the catalyst system, the yield and molecular weight of $\mathrm{PECH}$ increased largely $\mathrm{Nd}(\mathrm{acac})_{3}-\mathrm{Al}$ (iso- $\left.\mathrm{Bu}\right)_{3}-\mathrm{H}_{2} \mathrm{O}$ system was the most outstanding catalyst among the combinations examined. So the study was focused on the $\mathrm{Nd}$ catalyst system.

Polymerization of ECH with $\mathrm{Nd}(\text { acac })_{3}-\mathrm{Al}$ (iso-

$$
\mathrm{Bu})_{3}-\mathrm{H}_{2} \mathrm{O}
$$

The composition ratios of $\mathrm{Nd}(\mathrm{acac})_{3}-\mathrm{Al}$ (iso$\mathrm{Bu})_{3}-\mathrm{H}_{2} \mathrm{O}$ catalyst system are the most important factors influencing $\mathrm{ECH}$ polymerization. Table II shows the effects of the $\mathrm{H}_{2} \mathrm{O} / \mathrm{Al}$ molar ratio on the molecular weight, yield, and crystallinity of $\mathrm{PECH}$. It was seen that the inherent viscosity $[\eta]$ and yield of $\mathrm{PECH}$ increased greatly by the addition of a small amount of water into the catalyst system. The amount of water is not critical in the range of $\mathrm{H}_{2} \mathrm{O} / \mathrm{Al}=0.1-0.5$ for obtaining $\mathrm{PECH}$ with high molecular weight and high yield. The crystallinity $(10-20 \%)$ of PECH so prepared was much lower than that of polymer produced by zinc catalyst system. ${ }^{2}$

At a $\mathrm{H}_{2} \mathrm{O} / \mathrm{Al}$ molar ratio of 0.5 , the influence of the $\mathrm{Al} / \mathrm{Nd}$ molar ratio on polymerization was investigated in two ways: varying $\mathrm{Al}$ mole

Table I. ECH polymerization with $\mathrm{RE}(\mathrm{acac})_{3}-\mathrm{Al}(\text { iso- } \mathrm{Bu})_{3}-\mathrm{H}_{2} \mathrm{O}^{\mathrm{a}}$

\begin{tabular}{ccccccccccc}
\hline \multicolumn{1}{c}{$\mathrm{RE}$} & $\mathrm{La}$ & $\mathrm{Pr}$ & $\mathrm{Nd}$ & $\mathrm{Sm}$ & $\mathrm{Eu}$ & $\mathrm{Gd}$ & $\mathrm{Dy}$ & $\mathrm{Yb}$ & $\mathrm{Y}$ & $\mathrm{b}$ \\
\hline $\mathrm{Yield} / \mathrm{wt} \%$ & 30 & 43 & 51 & 53 & 21 & 55 & 57 & 60 & 60 & 23 \\
{$[\eta]$} & 4.4 & 4.1 & 6.5 & 4.5 & 3.4 & 3.6 & 4.0 & 3.7 & 4.1 & 0.9 \\
$\bar{M}_{v} / \times 10^{5}$ & 10.7 & 9.8 & 16.5 & 10.9 & 7.9 & 8.6 & 9.6 & 8.8 & 9.8 & 1.7 \\
\hline
\end{tabular}

a $\mathrm{Al} / \mathrm{RE}=8 ; \mathrm{H}_{2} \mathrm{O} / \mathrm{Al}=0.5 ; \mathrm{RE}, 8 \times 10^{-3} \mathrm{moll}^{-1}, 80^{\circ} \mathrm{C}, 2 \mathrm{~h} ; \mathrm{ECh}, 1.2 \mathrm{~g}$; toluene, $5 \mathrm{ml}$ (amounts of ECH and solvent are the same in the following tables and figures).

b $\mathrm{Al}$ (iso- $\mathrm{Bu})_{3}-\mathrm{H}_{2} \mathrm{O}(1: 0.5)$ catalyst system at the corresponding condition. 
Table II. Effect of $\mathrm{H}_{2} \mathrm{O} / \mathrm{Al}$ molar ratio on $\mathrm{ECH}$ polymerization ${ }^{\mathrm{a}}$

\begin{tabular}{lccc}
\hline $\mathrm{H}_{2} \mathrm{O} / \mathrm{Al}$ & Yield/wt\% & {$[\eta]$} & Crystallinity/\% \\
\hline 0 & 1 & 2.1 & 24 \\
0.1 & 43 & 5.6 & 12 \\
0.2 & 46 & 5.2 & 15 \\
0.4 & 50 & 5.3 & 18 \\
0.5 & 51 & 6.5 & 21 \\
0.6 & 27 & 5.0 & 21 \\
0.8 & 10 & 3.5 & 21 \\
\hline
\end{tabular}

a $\mathrm{Al} / \mathrm{Nd}=8,80^{\circ} \mathrm{C}, 2 \mathrm{~h}$.

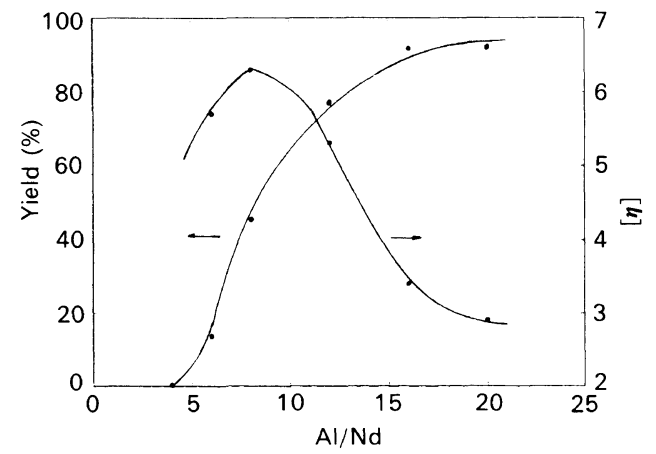

Figure 1. Influence of the $\mathrm{Al} / \mathrm{Nd}$ molar ratio on $\mathrm{ECH}$ polymerization. $\mathrm{Nd}: 8 \times 10^{-3} \mathrm{moll}^{-1}, 80^{\circ} \mathrm{C}, 2 \mathrm{~h}$.

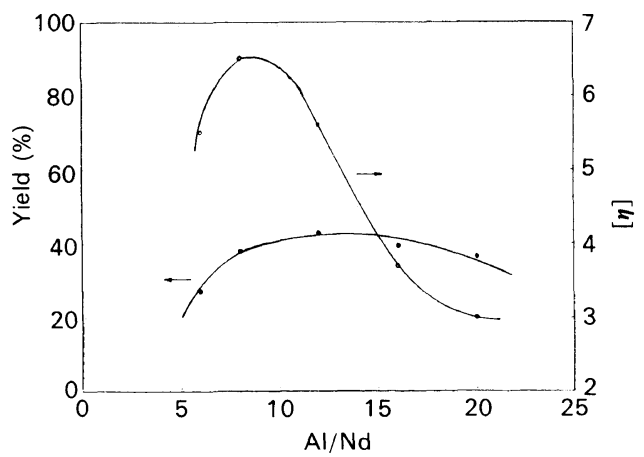

Figure 2. Influence of the $\mathrm{Al} / \mathrm{Nd}$ molar ratio on $\mathrm{ECH}$ polymerization. $\mathrm{Al}$ : $6.6 \times 10^{-2} \mathrm{moll}^{-1}, 80^{\circ} \mathrm{C}, 2 \mathrm{~h}$.

while heeping $\mathrm{Nd}$ and a constant and vice versa. The results are shown in Figures 1 and 2. It was found that the yield of PECH increased with $\mathrm{Al}$ concentration in catalyst system (Figure 1); on the other hand, the yield of $\mathrm{PECH}$ decreased with decreasing $\mathrm{Nd}$

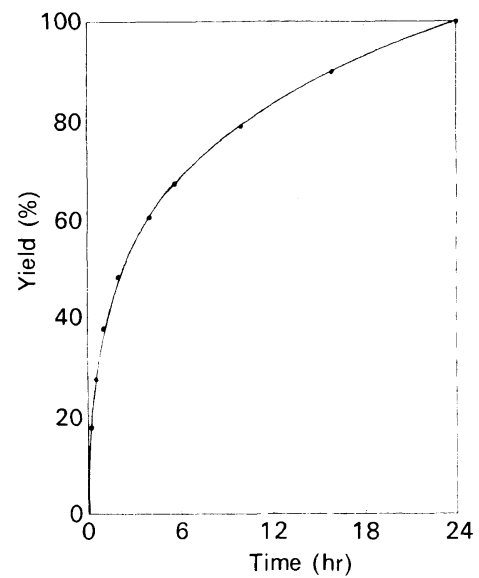

Figure 3. The rate of $\mathrm{ECH}$ polymerization with $\mathrm{Nd}(\mathrm{ac}-$ ac) ${ }_{3}-\mathrm{Al}(\text { iso- } \mathrm{Bu})_{3}-\mathrm{H}_{2} \mathrm{O}(1: 8: 4)$ catalyst system at $80^{\circ} \mathrm{C}$.

concentration (Figure 2). It was notable that the molecular weight of PECH largely depended on $\mathrm{Al} / \mathrm{Nd}$ molar ratio. The optimum $\mathrm{Al} / \mathrm{Nd}$ molar ratio for high $[\eta]$ is 8 . Similar results were observed for other rare earth coordination catalysts. Since $\mathrm{Al}(\text { iso- } \mathrm{Bu})_{3}-\mathrm{H}_{2} \mathrm{O}$ (1:0.5) could initiate $\mathrm{ECH}$ polymerization to give PECH with much lower molecular weight $\left(10^{4}-10^{5}\right)$, we postulated that rapid decreasing of $[\eta]$ in the high $\mathrm{Al} / \mathrm{Nd}$ ratio region might be caused by the coexistence of active species produced by excess $\mathrm{Al}(\text { iso- } \mathrm{Bu})_{3}-\mathrm{H}_{2} \mathrm{O}(1: 0.5)$ in the catalyst system. It seems that a kind of bimetallic catalyst species, involving $\mathrm{Al}$ and $\mathrm{Nd}$ in certain molar ratio, was responsible for the high polymerization degree of $\mathrm{PECH}$ obtained at $\mathrm{Al} / \mathrm{Nd}=8$.

The rate of $\mathrm{ECH}$ polymerization with $\mathrm{Nd}(\text { acac })_{3}-\mathrm{Al}(\text { iso- } \mathrm{Bu})_{3}-\mathrm{H}_{2} \mathrm{O}(1: 8: 4)$ can be seen from Figure 3 . The polymerization rate was fairly high in the first hour, and decreased gradually with time. The declination of the polymerization rate may be caused by reduction of the active center number, or/and insufficient diffusion of ECH molecules to the propagation species due to the increasing viscosity of the polymerization solution. Further kinetic study is described eleswhere. ${ }^{13}$

The polymerization was greatly influenced 
by the solvent used. A solution polymerization of $\mathrm{ECH}$ took place either in toluene or in dichloromethane. But, $\mathrm{PECH}$ was precipitated during polymerization with aliphatic hydrocarbon as solvent. Toluene appeared more preferable for the polymerization, as shown in Table III. The activity order was toluene » dichloromethane $>n$-hexane $>$ acetone. The $\mathrm{Nd}(\mathrm{acac})_{3}-\mathrm{Al}(\text { iso- } \mathrm{Bu})_{3}-\mathrm{H}_{2} \mathrm{O}$ catalyst system showed no activity for $\mathrm{ECH}$ polymerization in acetone, because the solvent itself coordinated with the catalyst and thus prohibited the coordination of ECH with the active species, which was one of the key steps for ring-opening

Table III. Effect of solvent ${ }^{\mathrm{a}}$

\begin{tabular}{rcccc}
\hline Solvent & Toluene & $\begin{array}{c}\text { Dichloro- } \\
\text { methane }\end{array}$ & $n$-Hexane & Acetone \\
\hline $\begin{array}{r}\text { Yield } / \\
\text { wt } \%\end{array}$ & 66 & 26 & 15 & 0 \\
\hline
\end{tabular}

a $\mathrm{Al} / \mathrm{Nd}=8, \mathrm{H}_{2} \mathrm{O} / \mathrm{Al}=0.5,35^{\circ} \mathrm{C}, 16 \mathrm{~h}$.

Table IV. Effect of polymerization temperature ${ }^{a}$

\begin{tabular}{ccc}
\hline Temp. $/{ }^{\circ} \mathrm{C}$ & Yield $/$ wt $\%$ & {$[\eta]$} \\
\hline 30 & 12 & 5.9 \\
50 & 32 & 7.0 \\
60 & 35 & 6.9 \\
70 & 40 & 6.3 \\
80 & 50 & 6.3 \\
100 & 55 & 4.1 \\
\hline
\end{tabular}

a $\mathrm{Al} / \mathrm{Nd}=8, \mathrm{H}_{2} \mathrm{O} / \mathrm{Al}=0.5,2 \mathrm{~h}$, toluene.

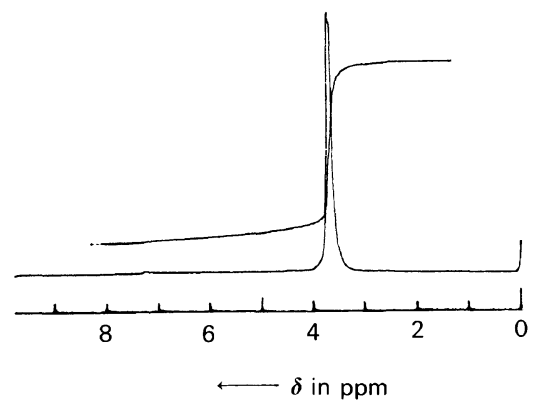

Figure 4. The ${ }^{1} \mathrm{H}$ NMR spectrum of $\mathrm{PECH}$. Solvent, $\mathrm{CDCl}_{3}$; internal reference, TMS. polymerization of alkylene oxide catalyzed by coordination catalyst. Using toluene as the polymerization solvent, the effect of polymerization temperature on the polymerization was examined and the results are summarized in Table IV.

PECH so prepared was characterized by ${ }^{1} \mathrm{H}$ NMR spectroscopy, as shown in Figure 4. The three different kinds of hydrogens in PECH $\left(-\mathrm{CH}_{2} \mathrm{Cl},-\mathrm{CH}-\right.$, and $\left.-\mathrm{CH}_{2}-\right)$ gave an overlapping signal at $\delta=3.6-3.8 \mathrm{ppm}$.

Character of the $\mathrm{Nd}(\text { acac })_{3}-\mathrm{Al}(\text { iso- } \mathrm{Bu})_{3}-\mathrm{H}_{2} \mathrm{O}$ Catalyst System

$\mathrm{Al}(\text { iso- } \mathrm{Bu})_{3}-\mathrm{H}_{2} \mathrm{O}(1: 0.5)$, acting as a Lewis acid, can be used to catalyze the polymerization of tetrahydrofuran (THF), which is known to be polymerized only by a cationic mechanism. ${ }^{14}$ In order to check the character of the $\mathrm{Nd}(\mathrm{acac})_{3}-\mathrm{Al}(\text { iso- } \mathrm{Bu})_{3}-\mathrm{H}_{2} \mathrm{O}$ catalyst system, the polymerization of THF with this catalyst was studied and the results are shown in Table V. The polymerization was carried out at $5^{\circ} \mathrm{C}$ for $24 \mathrm{~h}$ with $\mathrm{ECH}$ as a promoter by Saegusa's method. ${ }^{14}$ The catalyst system with $\mathrm{Al} / \mathrm{Nd}>10$ showed the same activity as that of $\mathrm{Al}$ (iso- $\mathrm{Bu})_{3}-\mathrm{H}_{2} \mathrm{O}(1: 0.5)$; when $\mathrm{Al} /$ $\mathrm{Nd} \leq 8$. However, only a trace of polymer was obtained. The trace polymer was determined as $\mathrm{PECH}$ because it was insoluble in the solvent of poly(tetrahydrofuran), i.e., benzene.

Table $\mathbf{V}$. The polymerization of $\mathrm{THF}^{\mathrm{a}}$

\begin{tabular}{|c|c|c|c|c|}
\hline Catalyst system & $\mathrm{Al} / \mathrm{mol}$ & $\mathrm{Nd} / \mathrm{mol}$ & $\mathrm{Al} / \mathrm{Nd}$ & Yield $/$ wt $\%$ \\
\hline $\begin{array}{l}\mathrm{Al} \text { (iso- } \mathrm{Bu})_{3}-\mathrm{H}_{2} \mathrm{O} \\
\quad(1: 0.5)\end{array}$ & 1.23 & 0 & - & 76 \\
\hline $\begin{array}{c}\mathrm{Nd}(\mathrm{acac})_{3}-\mathrm{Al} \text { (iso- } \\
\mathrm{Bu})_{3}-\mathrm{H}_{2} \mathrm{O}\end{array}$ & 1.23 & 0.031 & 40 & 76 \\
\hline \multirow[t]{5}{*}{$\left(\mathrm{H}_{2} \mathrm{O} / \mathrm{Al}=0.5\right)$} & 1.23 & 0.062 & 20 & 74 \\
\hline & 1.23 & 0.082 & 15 & 71 \\
\hline & 1.23 & 0.123 & 10 & 29 \\
\hline & 1.23 & 0.154 & 8 & b \\
\hline & 1.23 & 0.205 & 6 & b \\
\hline
\end{tabular}


It was indicated that the cationic character of $\mathrm{Al}$ (iso- $\mathrm{Bu})_{3}-\mathrm{H}_{2} \mathrm{O}$ system became a coordination anionic one gradually with the addition of $\mathrm{Nd}(\mathrm{acac})_{3}$. A complete coordination anionic feature was shown by $\mathrm{Nd}(\mathrm{acac})_{3}-\mathrm{Al}$ (iso$\mathrm{Bu})_{3}-\mathrm{H}_{2} \mathrm{O}\left(\mathrm{H}_{2} \mathrm{O} / \mathrm{Al}=0.5\right)$ at $\mathrm{Al} / \mathrm{Nd}=8$.

The coordination anionic feature of the $\mathrm{Nd}(\mathrm{acac})_{3}-\mathrm{Al}(\text { iso- } \mathrm{Bu})_{3}-\mathrm{H}_{2} \mathrm{O}(1: 8: 4)$ catalyst system was further demonstrated by the results of ECH-AGE and PO-AGE copolymerization ratios. Values obtained were $r_{1}(\mathrm{PO})=2.0$, $r_{2}(\mathrm{AGE})=0.5$; and $\dot{r}_{1}(\mathrm{ECH})=0.5, r_{2}(\mathrm{AGE})=$ 0.4 . The monomer reactivity order was $\mathrm{PO}>\mathrm{ECH}>\mathrm{AGE}$. The values of $r_{1}(\mathrm{PO})=0.6$ and $r_{2}(\mathrm{ECH})=1.8$ were reported ${ }^{15}$ by Ishida for $\mathrm{FeCl}_{3}-\mathrm{PO}$ catalyst. Since the ferric chloride catalyst generally has a cationic nature, the opposite results obtained by $\mathrm{Nd}(\mathrm{acac})_{3}-\mathrm{Al}$ (iso$\mathrm{Bu})_{3}-\mathrm{H}_{2} \mathrm{O}(1: 8: 4)$ catalyst system support the idea that this rare earth catalyst is a coordination anionic system.

Based on the above polymerization results, it is proposed that one kind of active species in $\mathrm{Nd}(\mathrm{acac})_{3}-\mathrm{Al}$ (iso- $\left.\mathrm{Bu}\right)_{3}-\mathrm{H}_{2} \mathrm{O}$ catalyst system, comprising of $\mathrm{Al}$ and $\mathrm{Nd}$ with certain molar ratio, and exhibiting the coordination anionic character, is responsible for the outstanding catalytic behaviour in the polymerization of $\mathrm{ECH}$.

\section{CONCLUSIONS}

The rare earth coordination catalysts, consisting of rare earth acetylacetonate RE$(\mathrm{acac})_{3}$, triisobutylaluminum, and water, can catalyze the polymerization of $\mathrm{ECH}$. The system of $\mathrm{Nd}(\mathrm{acac})_{3}-\mathrm{Al}(\text { iso- } \mathrm{Bu})_{3}-\mathrm{H}_{2} \mathrm{O}$ is the most outstanding catalyst among the nine combinations examined, with which PECH of high molecular weight and low crystallinity is prepared. The cationic character of $\mathrm{Al}$ (iso$\mathrm{Bu})_{3}-\mathrm{H}_{2} \mathrm{O}$ system becomes a coordination anionic one gradually with the addition of $\mathrm{Nd}(\mathrm{acac})_{3}$. A kind of bimetallic active species involving $\mathrm{Al}$ and $\mathrm{Nd}$ is proposed.

\section{REFERENCES}

1. E. J. Vandenberg, J. Polym. Sci., 47, 486 (1960).

2. H. L. Hsieh, J. Appl. Polym. Sci., 15, 2425 (1971).

3. Y. Kida, Y. Miura, K. Shikata, and K. Azuma, J. Polym. Sci., Polym. Chem. Ed., 13, 2835 (1975).

4. T. Oguni and H. Tani, J. Polym. Sci., Polym. Chem. Ed., 11, 573 (1973).

5. Z. Shen, Y. Zhang, and J. Peng, Journal of Zhejiang Univ., 19, 172 (1985).

6. Z. Shen, Y. Zhang, and G. Wang, Journal of Zhejiang Univ., 21, 114 (1987).

7. Z. Shen, J. Wu, and G. Wang, J. Polym. Sci., Polym. Chem. Ed., in press.

8. Y. Zhang, X. Cheng, and Z. Shen, Inorganica Chimica Acta, 55, 263 (1989).

9. Y. Zhang, and Z. Shen, Acta Polymeric Scinica, No. 6, 469 (1988).

10. J. Ouyan and Z. Shen, "Collection of Synthetic Rubber Catalyzed by Rare-Earth Catalysts," Science Press, Beijing, 1980.

11. Y. Lin, W. Zhang, Y. Sun, and S. Li, Journal East China Institute of Chemical Technology, No. 2, 181 (1983).

12. H. Wu, B. Wang, F. Wu, and S. Li, Polymer Communication (China), No. 1, 46 (1985).

13. J. Wu, Z. Shen, and X. He, Symposium on Polymers (Chinese Chemical Society Polymer Division), Preprints, Chengdu, 1989, p. 251.

14. T. Saegusa, H. Imai, and J. Furukawa, Makromol. Chem., 65, 60 (1963).

15. S. Ishida, Bull. Chem. Soc. Jpn., 33, 731 (1960). 